\title{
REFLEXÃO ACERCA DA FINALIDADE DA LEI ATRAVÉS DA ANÁLISE DA PEC DAS DOMÉSTICAS
}

\author{
Alana Petry ${ }^{1}$, Luana Cristina da Rosa ${ }^{2}$
}

Resumo: O trabalho doméstico é um dos mais antigos da humanidade, mas também é um dos mais defasados no tocante a direitos trabalhistas. A justificativa utilizada para isso seria a impossibilidade de se conceder igualdade jurídica entre os empregados domésticos e os demais, visto que não há entre eles igualdade fática. Contudo, a Constituição Federal de 1988 e a Emenda Constitucional 72/2013 trouxeram novos direitos a esta classe de trabalhadores. A pesquisa possui caráter qualitativo, bibliográfico e dedutivo, trazendo um breve relato da história dos empregados domésticos. Tem como objetivo analisar a Emenda Constitucional 72/2013, refletindo sobre a finalidade da lei. Conclui-se que a norma constitucional analisada influi no comportamento e na realidade social e também atende aos interesses da classe dominante, daqueles que possuem interesse na manutenção e na continuidade do trabalho doméstico. Assim, não há dúvida de que o direito exerce um controle sobre as pessoas e a sociedade, através dos usos, costumes, práticas sociais e das leis.

Palavras-chave: Trabalhadores domésticos. Direitos. Finalidade da lei.

\section{INTRODUÇÃO}

O trabalho humano é considerado uma atividade essencial na vida dos indivíduos na sociedade moderna e consiste em um dos pilares do sistema capitalista de produção. Dentre as diversas atividades laborais existentes na atualidade, destaca-se aquela desenvolvida no âmbito doméstico, que é uma das mais antigas da humanidade, bem como se reveste de características peculiares, que a diferencia das demais espécies de relações de trabalho.

Essa pesquisa tratará da análise da PEC das Domésticas (Proposta de Emenda à Constituição), que resultou na promulgação da Emenda Constitucional 72/2013, responsável por estabelecer uma ampliação aos direitos dos empregados domésticos, categoria que soma, somente no Brasil,

1 Acadêmica do curso de Direito no Centro Universitário UNIVATES. apetry@univates.br

2 Acadêmica do curso de Direito no Centro Universitário UNIVATES. lu.luanadarosa@gmail.com 
aproximadamente sete milhões de trabalhadores e emprega, em sua grande maioria, mulheres negras e de baixa escolaridade, conforme dados divulgados pela Organização Internacional do Trabalho (OIT, 2010).

Em nosso país, a classe dos empregados domésticos permaneceu excluída de qualquer benefício de cunho trabalhista ou previdenciário durante um longo período, o que demonstra que a herança da época colonial continuou a influenciar a sociedade brasileira mesmo depois da abolição do trabalho escravo. Somente a partir de 1972, com a Lei $n^{\circ} 5.859$, que se pode afirmar que essa categoria passou a ser incluída expressamente no ordenamento jurídico. Com a Constituição Federal de 1988 foram acrescidos mais oito novos direitos à categoria e, finalmente, com a Emenda Constitucional 72/2013, dezesseis novos direitos foram estendidos aos domésticos, representando um grande avanço legislativo.

Entretanto, a ampliação do rol de direitos constantes no parágrafo único do art. $7^{\circ}$ da Constituição Federal não significa que a desigualdade entre os empregados domésticos e os demais trabalhadores tenha sido de fato superada, uma vez que "a imposição de uma ordem social não se realiza sem que surjam conflitos relativos às regras sociais" (SABADELL, 2013, p. 70). Por esse motivo, esse trabalho objetiva analisar a Emenda Constitucional 72/2013 sob um viés filosófico e sociológico, partindo do pressuposto de que a lei é um instrumento de ação do Estado, que sofre, geralmente, influências axiológicas, e da noção de que "o direito é a forma específica de controle social nas sociedades complexas" (SABADELL, 2013, p. 139).

O objetivo geral do artigo é averiguar a finalidade da lei a partir da norma constitucional supracitada, desenvolvendo-se através das respostas de quatro questionamentos: De qual forma a lei influi na prática social?; Que força ela tem para mudar o comportamento social?; O conteúdo da lei relacionase efetivamente com o comportamento social?; Seu cumprimento é eficaz?. Quanto à metodologia utilizada, trata-se de pesquisa de caráter qualitativo, por tratar de investigar valores e permitir espaço para interpretações, possuindo cunho exploratório; bibliográfico, uma vez que é elaborada com base em livros publicados na área do direito; dedutivo, por valer-se de argumentos gerais para chegar a conclusões particulares.

Para concretizar os objetivos propostos, o presente trabalho estruturase em cinco seções: Introdução; Breve histórico da categoria dos empregados domésticos; De qual forma a lei influi na prática social e que força ela tem para mudar o comportamento social; O conteúdo da lei relaciona-se efetivamente com o comportamento social e o seu cumprimento é eficaz?; e Considerações finais. 


\section{BREVE HISTÓRICO DA CATEGORIA DOS EMPREGADOS DOMÉSTICOS}

A atividade doméstica está vinculada com a própria história da humanidade, se relacionando com os fenômenos da escravidão e da colonização. Apesar de sua longa trajetória, o trabalho doméstico nunca gozou de prestígio durante a história da humanidade, visto que geralmente consistia em atribuição dos servos e escravos (MARTINS, 2007). Geralmente, é qualificado como uma atividade de valor econômico pouco significativo, exercida por pessoas sem qualificação profissional e, muitas vezes, em condições de vulnerabilidade social (ORGANIZAÇÃO INTERNACIONAL DO TRABALHO - OIT, 2010).

De acordo com Martins (2007), em nosso país essa relação de trabalho teve origem com os escravos africanos, que além do trabalho braçal nas lavouras, também eram designados para o exercício de trabalhos domésticos, principalmente as mulheres. Inicialmente, não havia legislação específica referente ao trabalho doméstico, sendo utilizados alguns preceitos do Código Civil por analogia, no que dizia respeito à locação de serviços (MARTINS, 2007). Com relação à Consolidação das Leis do Trabalho (CLT), esta dispõe que seus preceitos não se aplicam aos empregados domésticos, salvo quando for, em cada caso, determinado expressamente o contrário.

Como já afirmado na seção anterior, apenas com a Lei $n^{0} 5.859$, de 11 de dezembro de 1972, foram especificados os direitos trabalhistas do empregado doméstico e instituída sua inclusão obrigatória na Previdência Social. A referida lei conceitua empregado doméstico como toda pessoa que presta serviços de forma constante e com fim não lucrativo à pessoa ou à família na residência destas. A Cartilha de Perguntas e Respostas sobre Trabalho Doméstico elaborada pelo Ministério do Trabalho e do Emprego explica que integram a categoria dos trabalhadores domésticos o empregado, a babá, a governanta, o cozinheiro, a lavadeira, o faxineiro, o vigia, o motorista particular, o jardineiro, o acompanhante de idosos e o caseiro, quando o local onde exerce sua atividade não possui finalidade lucrativa.

Com a Constituição Federal de 1988, que representou "um grande avanço na proteção jurídica do trabalho doméstico" (OLIVEIRA, 2013, p. 237), os direitos dos empregados domésticos tornaram-se direitos constitucionais e foram definidos quais desses direitos pertencentes aos trabalhadores urbanos e rurais brasileiros se aplicam à categoria, uma vez que se trata de uma relação de trabalho com características próprias e diferenciadas. Segundo a autora citada, desde a abolição da escravatura até o advento da Carta Magna de 1988, verifica-se uma atuação quase nula do Poder Legislativo no tocante à questão do trabalho doméstico. Nesse mesmo sentido, Perrini (2013, p. 268) afirma que "o preconceito existente com relação ao trabalho doméstico fica bem retratado pela morosa evolução dos seus direitos trabalhistas". 
Por fim, com a Emenda Constitucional 72/2013, houve uma ampliação substancial do rol de direitos trabalhistas dos empregados domésticos, que vem gerando grande repercussão social e econômica e que representa uma possibilidade de ruptura no tocante à desigualdade de tratamento entre a categoria doméstica e as demais categorias de trabalhadores até então positivada na norma constitucional. No entanto, é preciso investigar se apenas a previsão constitucional será capaz de superar a situação de desigualdade que perdura durante longo tempo na sociedade brasileira.

\section{DE QUAL FORMA A LEI INFLUI NA PRÁTICA SOCIAL E QUE FORÇA ELA TEM PARA MUDAR O COMPORTAMENTO SOCIAL}

Analisando a história brasileira, é possível afirmar que o empregado doméstico sempre foi considerado um trabalhador de nível inferior aos outros trabalhadores. Esse fato tem origem na escravidão, visto que foram os escravos africanos que deram início ao trabalho doméstico em nosso país (MARTINS, 2007), conforme já mencionado na seção anterior. Sendo assim, essa categoria também foi tratada de forma diferente pelo ordenamento jurídico, dificilmente conquistando garantias normativas. Segundo Delgado (2014), a justificativa utilizada para isso seria a impossibilidade de se conceder igualdade jurídica entre os empregados domésticos e os demais, visto que não há entre eles igualdade fática.

Dito isso, verifica-se que a Emenda Constitucional 72/2013 representa um grande avanço legislativo, pois estende aos empregados domésticos dezesseis direitos trabalhistas que já eram assegurados aos trabalhadores urbanos e rurais. Porém, a ampliação do rol de direitos previstos no parágrafo único do art. $7^{\circ}$ da Constituição Federal não conduz automaticamente à concretização da igualdade entre as diferentes categorias de trabalhadores.

Segundo Boskovic e Villatore (2013), é necessário realizar uma análise acerca dos reais motivos da promulgação da Emenda Constitucional 72/2013, pois ao contrário do que foi divulgado pela imprensa, o Brasil ainda se encontra muito distante de concretizar a plena igualdade de direitos entre os trabalhadores celetistas e domésticos. Isso ocorre, sobretudo, devido às peculiaridades que a relação de trabalho doméstico apresenta, dificultando a aplicação de alguns direitos adquiridos, bem como em virtude do estigma social e jurídico que historicamente acompanha a classe doméstica brasileira.

Analisando a votação e a aprovação da Emenda Constitucional 72/2013, conclui-se que a principal motivação da Câmara dos Deputados e do Senado Federal foi baseada em critérios econômicos. Para Perrini (2013), ao aprovar a referida norma, o Congresso Nacional aplicou a lei econômica da oferta e da procura, visto que os domésticos integram uma categoria que está em falta, em virtude do desenvolvimento econômico e do fortalecimento do mercado de trabalho, que possibilitou aumento no número de vagas em outras áreas. 
Sendo assim, a principal finalidade da Emenda, conforme o autor supracitado, foi "valorizar" a profissão de empregado doméstico, objetivando a manutenção dos trabalhadores nessa categoria. Destarte, a lei influi no meio social disseminando uma ideia positiva acerca desse trabalho, com o intuito de reter mão de obra nessa categoria profissional. Entretanto, essa ideia positiva não tem nenhuma relação com a promoção da igualdade entre os trabalhadores ou com o fim da discriminação, pois seu principal fundamento é o fator econômico, guiado pelos interesses das classes detentoras do poder.

Nesse sentido, é possível verificar que, visando proteger interesses econômicos, os detentores do poder utilizam-se dos meios de comunicação e veiculação de informações para transmitir a ideia de que a lei surgiu com a finalidade de valorizar e proteger os trabalhadores domésticos, bem como de resolver todos os problemas sociais existentes. Assim, percebe-se o fenômeno da opinião pública, a qual pode ser compreendida como a opinião coletiva de uma determinada população acerca dos atos do governo e de assuntos relacionados com a vida em sociedade, sendo que esta exerce influência sobre a produção legislativa e sobre o modo como a população encara as leis criadas, geralmente, pelo Poder Legislativo. Dessa forma, os próprios indivíduos podem exercer certa pressão sobre a criação ou revogação de determinadas normas (NUNES, 2015).

Conforme Nunes (2015), o verdadeiro poder social fundamenta-se no fenômeno da opinião pública, que impõe determinadas posições como verdades absolutas através dos detentores do poder, dos parceiros econômicos e dos meios de comunicação. Por esse motivo, nem sempre a opinião pública é, de fato, o que parece ser, uma vez que reflete as imposições sofridas e é, muitas vezes, controlada pelos detentores do poder e dos meios de comunicação. Apesar disso, Nunes (2015) ressalta que a opinião pública é muito importante no contexto do Estado Democrático de Direito, uma vez que representa os anseios sociais, além de servir como "um instrumento de controle público do poder" (STRECK; MORAIS, 2006, p. 191), isto é, atua como mecanismo que controla a publicidade dos atos decisórios do governo.

Destarte, o regime democrático traz consigo a crença de que o interesse comum e a opinião pública serão observados pelos representantes da população no momento de elaboração das leis. Todavia, essa representatividade é apenas formal e não real, como enfatiza Nunes (2015). Sendo assim, o fenômeno da opinião pública e a representatividade apenas formal dos anseios sociais podem ser observados no período de votação e de promulgação da PEC das Domésticas: a interminável discriminação sofrida pelos empregados domésticos foi atenuada, através da intensa campanha midiática realizada, pela disseminação de que a almejada igualdade de direitos havia sido conquistada com a promulgação da Emenda.

Diante do exposto, cabe mencionar que o direito e a produção legislativa são produtos da sociedade, pois estão inseridos em um contexto social, cultural, 
político e econômico. Em virtude disso, são influenciados pelos interesses e pressões de grupos sociais, refletindo as características da sociedade, mas também atuando como fatores determinantes na realidade social (NUNES, 2015). Segundo Iamundo (2014, p. 209), “o discurso jurídico é, antes de tudo, a produção e reprodução de uma correlação de forças internas". No mesmo sentido, posiciona-se Adeodato (2013, p. 45), que enfatiza que "em lugar da cultura do distanciamento burocrático, [...] há a cultura da troca de favores e da boa vizinhança, em vez da neutralidade eficiente do Estado, o nepotismo e o corporativismo".

Além disso, segundo Sabadell (2013), o direito em sentido amplo - e a lei considerada como meio utilizado pelo Estado para efetivar as normas que compõem o sistema jurídico - é um instrumento necessário para a legitimação do poder político. Isso ocorre porque "a existência de um sistema jurídico está ligada à ideia do justo. Se as leis são respeitadas por todos, as pessoas acreditarão que a justiça prevalece" e "a existência do direito e o respeito a ele oferecem ao cidadão uma sensação de segurança" (SABADELL, 2013, p. 110).

Nesse sentido, Nader (2015) reafirma a importância dessa sensação de segurança jurídica ao bem-estar das pessoas, uma vez que esta é para os cidadãos a garantia efetiva de que os interesses principais dos seres humanos estão protegidos, gerando assim o equilíbrio e a tranquilidade na sociedade.

Portanto, é possível afirmar que a lei influi no meio social como um instrumento de transformação e controle social, visto que possui esse potencial, pois é emanada do Estado, detentor exclusivo do monopólio de criação das leis. Entretanto, ela acaba sendo orientada e influenciada pelo poder, pelas questões políticas, pela opinião pública e, principalmente, pelo fator econômico, como bem abordado por Nunes (2015).

Segundo Nunes (2015, p. 181), “o aspecto econômico, preponderante no meio social, distorce inclusive valores e exercícios dos próprios direitos dos envolvidos numa relação interindividual tomados dentro do espaço coletivo". Sendo assim, o direito torna-se mais racional, pois é guiado pela relação custobenefício, como a lei econômica da oferta e da procura, que foi o fundamento utilizado pelos deputados e senadores que aprovaram a norma em questão.

De acordo com Dias (2014, p. 199), as leis são reflexo dos interesses das classes e grupos dominantes e "a inter-relação entre grupos e classes sociais, definidas pelo fator econômico, determina as estruturas jurídicas". Desse modo, é inegável que a produção legislativa acabe por ser profundamente influenciada pela economia. Em vista disso, muitas leis serão criadas visando atender a interesses econômicos e não voltadas para o bem-estar da população.

A lei tem força para mudar o comportamento social devido a consequências históricas, pois, geralmente, são vistas como dogmas supremos, que possuem legitimidade, porque emanadas das autoridades competentes e criadas seguindo um procedimento formal, passando a incidir sobre o 
pensamento e o comportamento da população. De acordo com Sabadell (2013), na contemporaneidade, o processo de legitimação depende da observância às regras e aos procedimentos definidos pelo ordenamento jurídico, em nítida submissão ao princípio da legalidade.

No entanto, a lei, como instrumento de ação do Estado, muitas vezes esconde intenções não declaradas daqueles que as elaboram ou executam, como, por exemplo, a Emenda Constitucional 72/2013. E é nesse sentido, de acordo com Nunes (2015) que se pode afirmar que nem sempre a lei é criada para ser aplicada, ou que é criada com a finalidade de efetivamente mudar o comportamento ou a realidade social.

Com base em Nunes (2015), o sucesso de cada lei não está necessariamente relacionado com a sua aplicação no meio social. $\mathrm{O}$ autor corrobora essa afirmação esclarecendo que existem leis que são bem-sucedidas justamente por não serem aplicadas, porque sua principal finalidade está escondida, disfarçada. Portanto, é possível concluir que a principal finalidade da Emenda Constitucional 72/2013 é influir no meio social atenuando a pressão das forças sociais e ideológicas, estabelecendo uma igualdade - imaginária - entre os empregados domésticos e os demais trabalhadores, visto que a categoria doméstica é alentada pela perspectiva de que os direitos previstos na Constituição serão futuramente realizados.

Cabe ressaltar a posição de Dias (2014), que assevera que as normas jurídicas visam influir no meio social, promovendo estabilidade e impedindo que ocorram mudanças bruscas na ordem social. Nesse sentido, o autor destaca que as leis buscam produzir apenas alterações fragmentadas, que não transformem significativamente a estrutura social. Portanto, "embora o Direito não seja um instrumento contrário a mudança, devido às suas características e funções, atua de modo geral como se o fosse" (DIAS, 2014, p. 198).

Para Perrini (2013), se os legisladores quisessem, de fato, promover a igualdade entre os domésticos e as demais categorias, não teriam apenas alterado o parágrafo único do art. $7^{\circ}$ da Constituição Federal, mas sim extinguido o referido parágrafo e incluído os empregados domésticos no caput do artigo. Isso se explica pelo fato de que o real objetivo do Congresso Nacional não era promover a igualdade material ou transformar o meio social, mas sim divulgar na mídia uma fictícia isonomia, para atingir fins econômicos. Com isso, verifica-se que a distinção entre os trabalhadores domésticos e os demais trabalhadores continua existindo, o que perpetua a distância entre o previsto nas normas e a realidade social.

\section{O CONTEÚDO DA LEI RELACIONA-SE EFETIVAMENTE COM O COMPORTAMENTO SOCIAL E O SEU CUMPRIMENTO É EFICAZ?}

Antes da criação da Emenda Constitucional 72/2013, a situação dos empregados domésticos era considerada ruim, pois, segundo a Pesquisa 
Nacional por Amostra de Domicílios (PNAD) do ano de 2009, feita pelo IBGE, o número de trabalhadores domésticos com carteira assinada correspondia a somente $27,62 \%$ do total de trabalhadores domésticos do país (DINIZ, 2014). Deste número, conforme apontado por Diniz, 21,38\% ganhavam de R \$ 0,01 até meio salário mínimo; $21,38 \%$ ganhavam de meio salário mínimo até menos de um salário mínimo; 19,38\% ganhavam um salário mínimo; e apenas 1,30\% dos domésticos tinham Fundo de Garantia por Tempo de Serviço (FGTS) e seguro desemprego.

Assim, com a necessidade de leis mais protetivas ao trabalhador, fiscalização do cumprimento das mesmas e imposição de multas, a fim de que fossem efetivadas com eficácia, foi criada a Emenda Constitucional 72/2013 que traz a seguinte redação:

Artigo único. O parágrafo único do art. $7^{\circ}$ da Constituição Federal passa a vigorar com a seguinte redação: Art. $7^{\circ}$ (...) Parágrafo único. São assegurados à categoria dos trabalhadores domésticos os direitos previstos nos incisos IV, VI, VII, VIII, X, XIII, XV, XVI, XVII, XVIII, XIX, XXI, XXII, XXIV, XXVI, XXX, XXXI e XXXIII e, atendidas as condições estabelecidas em lei e observada a simplificação do cumprimento das obrigações tributárias, principais e acessórias, decorrentes da relação de trabalho e suas peculiaridades, os previstos nos incisos I, II, III, IX, XII, XXV e XXVIII, bem como a sua integração à previdência social.

Passaram a fazer parte dos direitos da categoria dos trabalhadores domésticos:

I - relação de emprego protegida contra despedida arbitrária ou sem justa causa, nos termos de lei complementar, que preverá indenização compensatória, dentre outros direitos; II - segurodesemprego, em caso de desemprego involuntário; III - fundo de garantia do tempo de serviço; IV - salário mínimo, fixado em lei, nacionalmente unificado, capaz de atender a suas necessidades vitais básicas e às de sua família com moradia, alimentação, educação, saúde, lazer, vestuário, higiene, transporte e previdência social, com reajustes periódicos que lhe preservem o poder aquisitivo, sendo vedada sua vinculação para qualquer fim; VI - irredutibilidade do salário, salvo o disposto em convenção ou acordo coletivo; VII garantia de salário, nunca inferior ao mínimo, para os que percebem remuneração variável; VIII - décimo terceiro salário com base na remuneração integral ou no valor da aposentadoria;

IX - remuneração do trabalho noturno superior à do diurno; $X$ - proteção do salário na forma da lei, constituindo crime sua retenção dolosa; XII - salário-família pago em razão do dependente do trabalhador de baixa renda nos termos da lei; XIII - duração do trabalho normal não superior a oito horas diárias e quarenta e 
quatro semanais, facultada a compensação de horários e a redução da jornada, mediante acordo ou convenção coletiva de trabalho; XV - repouso semanal remunerado, preferencialmente aos domingos; XVI - remuneração do serviço extraordinário superior, no mínimo, em cinquenta por cento à do normal; XVII - gozo de férias anuais remuneradas com, pelo menos, um terço a mais do que o salário normal; XVIII - licença à gestante, sem prejuízo do emprego e do salário, com a duração de cento e vinte dias; XIX-licença-paternidade, nos termos fixados em lei; XXI - aviso prévio proporcional ao tempo de serviço, sendo no mínimo de trinta dias, nos termos da lei; XXII - redução dos riscos inerentes ao trabalho, por meio de normas de saúde, higiene e segurança; XXIV - aposentadoria. XXV - assistência gratuita aos filhos e dependentes desde o nascimento até 5 (cinco) anos de idade em creches e pré-escolas; XXVI - reconhecimento das convenções e acordos coletivos de trabalho; XXVIII - seguro contra acidentes de trabalho, a cargo do empregador, sem excluir a indenização a que este está obrigado, quando incorrer em dolo ou culpa; XXX - proibição de diferença de salários, de exercício de funções e de critério de admissão por motivo de sexo, idade, cor ou estado civil; XXXI - proibição de qualquer discriminação no tocante a salário e critérios de admissão do trabalhador portador de deficiência; XXXIII - proibição de trabalho noturno, perigoso ou insalubre a menores de dezoito e de qualquer trabalho a menores de dezesseis anos, salvo na condição de aprendiz, a partir de quatorze anos.

Porém, infelizmente, o conteúdo da lei não se relaciona efetivamente com o comportamento social, pois famílias de classe média lidam com a dificuldade de contratar um empregado doméstico porque não conseguem arcar com os custos do mesmo. Além disso, o empregador, na maioria das vezes, é ausente de sua residência, não tendo como controlar a jornada de seu empregado, a fim de contabilizar horas extras. Portanto, há dificuldade para realizar o controle das horas de repouso, bem como do intervalo intrajornada daquele trabalhador que dorme na residência.

O empregador doméstico não é empresa e não tem fins lucrativos (DINIZ, 2014), assim, geralmente, ter um empregado doméstico é uma necessidade para este empregador, pelo fato de estar com alguém doente na família que necessita de atenção especial ou pelo casal trabalhar e não ter tempo de fazer a limpeza da sua casa.

Por isso, é necessária a adoção de uma norma jurídica que atenda aos anseios dos trabalhadores domésticos, sem desvalorizar a classe, e que seja compatível com a realidade social existente, pois muitos direitos garantidos aos empregados domésticos, da forma que são, não são passíveis de cumprimento e assim acabam por não serem efetivados. 
No tocante ao cumprimento da lei ser eficaz, a eficácia da norma diz respeito a sua aptidão de produzir efeitos (NUNES, 2015), ou seja, é uma qualidade da norma que possui relação com a sua capacidade de produção concreta de efeitos (FERRAZ JUNIOR, 1998). Nessa lógica, Kelsen (1996) propõe a distinção entre vigência e eficácia, pois dizer que uma norma vale (é vigente) simboliza um conceito diferente do que se diz quando se afirma que ela é efetivamente aplicada e respeitada pelo corpo social.

Ademais, é importante trazer à tona a classificação das normas constitucionais segundo sua eficácia defendida por Silva (2007), dividindoas em normas de eficácia plena, contida e limitada. As primeiras são aquelas que produzem seus efeitos desde logo, isto é, são imediatamente aplicáveis; as segundas também produzem seus efeitos de forma imediata, porém, podem sofrer redução em sua eficácia por disposição de outras normas; e as terceiras dependem de uma regulamentação efetuada por outras normas.

Portanto, sob a perspectiva de uma análise formal e superficial, é possível afirmar que a Emenda Constitucional 72/2013 é eficaz, pois ela está vigente e apta a produzir efeitos na sociedade. Contudo, trata-se de uma norma constitucional de eficácia limitada, pois a efetivação de seus efeitos depende da criação de outras leis. Dessa maneira, em relação ao seu cumprimento, não podemos dizer que a Emenda Constitucional 72/2013 é totalmente eficaz, em vista de que mesmo ela estando em vigor e apta a produzir efeitos, ainda há muitos empregados domésticos que não tem seus direitos assegurados, pois acabam aceitando as condições impostas pelos empregadores para garantir o emprego.

Isso ocorre também porque, muitas vezes, a representação da classe doméstica pelas entidades sindicais não é efetiva, e esses trabalhadores acabam ficando desemparados. Geralmente, a atuação sindical e "os movimentos reivindicatórios são coibidos [...] por atitudes repressivas autoritárias, baseadas em políticas intervencionistas e centralizadoras do Estado" (TITTONI, 2007, p. $41)$.

Além disso, o cumprimento da Emenda também não é totalmente eficaz porque os empregadores, geralmente, não têm como garantir aos empregados domésticos os novos direitos previstos, pois, por exemplo, não conseguem controlar entrada, saída, hora extra, uma vez que não estão em casa durante o dia.

Apesar do conteúdo da norma dizer respeito ao comportamento social, a correspondência entre ambos não significa que a imposição normativa da lei será efetivamente observada no comportamento social, decorrendo desse fato a ineficácia do cumprimento da lei. A mera previsão legislativa não é suficiente para a garantia de direitos e nem para a efetivação da igualdade, visto que a relação doméstica possui características próprias e distintas das outras relações de trabalho. 
Com relação à eficácia da lei, Reale (2011) menciona que o poder da eficácia pode ser verificado em quatro hipóteses diferentes, sendo a mais delicada aquela que trata da norma de vigência puramente abstrata, que não produz uma experiência possível e realizável, não possuindo qualquer efetividade. Nessa sequência, importante mencionar o posicionamento de Weber (2012), que ao explicar os conceitos de vigência e eficácia da norma jurídica, afirma que o não cumprimento da norma não possui relação somente com a existência do aparato coativo que pertence ao Estado. A inobservância da lei e a sua consequente ineficácia são motivadas por razões de diferentes naturezas, como, por exemplo, o fator econômico apontado na seção anterior.

Deve-se levar em consideração também, o fato de que no rol dos direitos garantidos aos empregados domésticos, há aqueles que possuem aplicação imediata, mas existem vários que necessitam de regulamentação específica, em virtude da especificidade da relação doméstica. Sendo assim, é possível concluir que o cumprimento da Emenda não é de fato eficaz, porque embora garanta formalmente novos direitos aos trabalhadores domésticos, não garante a sua efetiva concretização, deixando espaço para que sejam modificados e adequados de acordo com o interesse do empregador, até que outra norma venha a regulamentá-los.

Nesse sentido, Dias (2014) ressalta que a mudança social ocorre de forma contínua na sociedade, entretanto, o impacto dessa mudança social dependerá do tempo e do espaço no qual atuará. Além disso, a mudança social também é influenciada por diversos fatores, que tendem a conduzir a sua efetivação na realidade, como o poder econômico e o poder ideológico, que controlam, muitas vezes, também a opinião pública. Coelho (1992, p. 67) afirma que "as pessoas que integram o estado exercem um certo tipo de poder sobre as demais e, em geral, lutam para se manter independentes da sociedade, acima dela".

Assim, o cumprimento da norma em estudo não é eficaz, pois o texto legal é incapaz de assegurar "as expectativas normativas" (NEVES, 2016, p. 53), atuando apenas como ferramenta que dissemina a ideia de isonomia fictícia. $\mathrm{O}$ autor chama esse tipo de norma jurídica de legislação-álibi ou legislação simbólica, que "é um mecanismo com amplos efeitos político-ideológicos [...] descarrega o sistema político de pressões sociais concretas, constitui respaldo eleitoral para os respectivos políticos-legisladores" (NEVES, 2016, p. 54). Em suma, esse tipo de legislação adia os "conflitos políticos sem resolver realmente os problemas sociais subjacentes" (NEVES, 2016, p. 54).

Portanto, talvez a intenção do legislador, influenciado por valores ideológicos/partidários e/ou econômicos, tenha sido justamente essa: criar apenas uma igualdade fictícia, mas de nível constitucional, divulgada pela mídia através da opinião pública como o fim da discriminação entre a categoria doméstica e os demais trabalhadores, mas que serve apenas como instrumento para manter a ordem e a estrutura sociais. 


\section{CONSIDERAÇÕES FINAIS}

Este estudo verificou que a Emenda Constitucional 72/2013 representa um grande avanço na legislação trabalhista brasileira relativa à categoria dos empregados domésticos. Não há como negar que essa norma é mais uma medida adotada pelo Estado e pela sociedade para promover uma maior igualdade entre os diferentes trabalhadores. Além disso, a ampliação do rol de direitos constitucionais previstos aos empregados domésticos representa uma importante conquista para essa categoria, que vem sendo excluída do ordenamento jurídico há centenas de anos.

No entanto, este trabalho realizou um estudo filosófico e sociológico da norma constitucional supracitada, partindo do pressuposto de que a lei é um instrumento de controle social utilizado pelo Estado e de que o direito deve ser compreendido levando-se em consideração a totalidade do sistema no qual ele está inserido, articulando-o com os inúmeros fatores pelos quais ele é atingido.

A pesquisa possibilitou concluir que a Emenda Constitucional 72/2013 influencia o comportamento e a realidade social, pois obsta a reivindicação exercida pelas forças sociais, uma vez que aquilo que os domésticos teriam a reivindicar já está contemplado na Constituição, embora sem ser efetivamente garantido. Em contrapartida, ela também atende aos interesses da classe dominante, daqueles que possuem interesse na manutenção e continuidade do trabalho doméstico e na não extinção de profissionais dessa categoria.

Dessa forma, as afirmações expostas ao longo do trabalho são corroboradas, visto que não há dúvida de que o direito exerce um controle sobre as pessoas e a sociedade, através dos usos, costumes, práticas sociais e das leis. Além disso, o direito não é a representação de um sistema intocável e interdependente, responsável por disseminar a imagem idealizada da justiça, que dá a cada um aquilo que é seu por direito, sem distinções. $O$ direito é influenciado por uma série de fatores na sociedade capitalista contemporânea, como o poder de grupos economicamente dominantes, que por sua vez pressionam a formação de uma opinião pública legitimadora do mesmo.

A Emenda Constitucional 72/2013 acalmou os anseios das forças sociais que reivindicavam a valorização dos domésticos, trabalhadores historicamente alocados em um limbo jurídico. E, simultaneamente, por apenas garantir uma igualdade fictícia, atendeu aos interesses da classe dominante economicamente interessada em manter mão de obra na categoria doméstica. Sendo assim, minimiza as pressões sociais através da regulamentação normativa sem, no entanto, solucionar os problemas sociais existentes.

Essa verdadeira finalidade da norma em análise evidencia que a lei esconde intenções não declaradas daqueles que as elaboraram ou influenciaram no momento de sua criação. Portanto, a lei é um meio de ação do Estado e talvez seja o instrumento de controle social - ou controle institucionalizado mais poderoso que o governo possua em relação aos cidadãos, podendo ser 
utilizado com o objetivo de orientação aos padrões pré-estabelecidos ou de fiscalização do comportamento social, sendo aplicado de forma difusa ou localizada, destinado ao controle de um determinado grupo, como ocorreu no caso dos trabalhadores domésticos.

\section{REFERÊNCIAS}

ADEODATO, João Maurício. Filosofia do direito: uma crítica à verdade na ética e na ciência. 5. ed. rev. e ampl. São Paulo: Saraiva, 2013. E-book. Disponível em: <http:// www.univates.br/biblioteca/e-books-minha-biblioeca?isbn= 9788502197916>. Acesso em: 21 maio. 2017.

BOSKOVIC, Alessandra Barichello; VILLATORE, Marco Antônio César. Trabalho decente doméstico e a necessidade de mais legislação para o Brasil ratificar a Convenção 189 da Organização Internacional do Trabalho e suas consequências sociais e econômicas. In: GUNTHER, Luiz Eduardo; MANDALOZZO, Silvana Souza Netto (Coords.). Trabalho doméstico: teoria e prática da Emenda Constitucional 72, de 2013. Curitiba: Juruá, 2013, p. 27-44.

BRASIL. Consolidação das Leis do Trabalho. Disponível em: <http:/ /www.planalto. gov.br/ccivil_03/decreto-lei/Del5452.htm>. Acesso em: 03 set. 2015.

BRASIL. Constituição Federal (1988). Disponível em: <http:/ /www.planalto.gov.br/ ccivil_03/Constituicao/Constituicao.htm>. Acesso em: 03 set. 2015.

BRASIL. Constituição Federal (1988). Emenda Constitucional nº 72, de 02 de abril de 2013. Altera a redação do parágrafo único do art. $7^{\circ}$ da Constituição Federal para estabelecer a igualdade entre os trabalhadores domésticos e os demais trabalhadores urbanos e rurais. Constituição da República Federativa do Brasil. Disponível em: <http://www.planalto.gov.br/ccivil_03/constituição/Emendas/Emc/emc72.htm>. Acesso em: 05 set. 2015.

BRASIL. Lei n. 5.859, de 11 de dezembro de 1972. Dispõe sobre a profissão de empregado doméstico e dá outras providências. Disponível em: http:/ /www. planalto.gov.br/ccivil_03/leis/15859.htm>. Acesso em: 05 set. 2015.

CHEMIN, Beatris F. Manual da Univates para trabalhos acadêmicos: planejamento, elaboração e apresentação. 3. ed. Lajeado: Univates, 2015.

COELHO, Fábio Ulhoa. Direito e poder: ensaio de epistemologia jurídica. São Paulo: Saraiva, 1992.

DELGADO, Mauricio Godinho. Curso de direito do trabalho. 13. ed. São Paulo: LTr, 2014.

DIAS, Reinaldo. Sociologia do Direito: a abordagem do fenômeno jurídico como fato social. 2. ed. rev. e ampl. São Paulo: Atlas, 2014. E-book. Disponível em: <http:/ / 
www.univates.br/biblioteca/e-books-minha-biblioeca?isbn=9788522485123 >. Acesso em: 21 maio. 2017.

DINIZ, Fernanda Soares. A EC 72/2013 e o trabalho doméstico no Brasil. 2014.

Disponível em: <http:/ /www.jurisway.org.br/v2/dhall.asp?id_dh=13764>. Acesso em: 03 set. 2015.

FERRAZ JUNIOR, Tércio Sampaio. Introdução ao Estudo do Direito. São Paulo: Atlas, 1988.

IAMUNDO, Eduardo. Sociologia e antropologia do direito. São Paulo: Saraiva, 2013.

KELSEN, Hans. Teoria Pura do Direito. Trad. João Batista Machado. 5. ed. São Paulo: Martins Fonte, 1996.

MARTINS, Sergio Pinto. Manual do Trabalho Doméstico. 9. ed. São Paulo: Atlas, 2007.

\section{MINISTÉRIO DO TRABALHO E EMPREGO. Cartilha Perguntas e Respostas}

Trabalho Doméstico. Brasília, DF, 2013. Disponível em: <http:/ / www.portal.mte.gov. br/trab_domestico/trabalho-domestico.htm>. Acesso em: 03 set. 2015.

NADER, Paulo. Filosofia do direito. 23. ed. Rio de Janeiro: Forense, 2015.

E-book. Disponível em: <http://www.univates.br/biblioteca/e-books-minhabiblioeca?isbn=9788530964757>. Acesso em: 21 maio. 2017.

NEVES, Marcelo. A constitucionalização simbólica. 3. ed. São Paulo: WMF Martins Fontes, 2016.

NUNES, Rizzatto. Manual de filosofia do direito. 6. ed. rev. e ampl. São Paulo: Saraiva, 2015. E-book. Disponível em: <http:/ / www.univates.br/biblioteca/e-booksminha-biblioeca?isbn=9788502221703>. Acesso em: 17 maio. 2016.

OLIVEIRA, Nancy Mahra de Medeiros Nicolas. Emenda Constitucional 72/13: superação da desigualdade? In: GUNTHER, Luiz Eduardo; MANDALOZZO, Silvana Souza Netto (Coords.). Trabalho doméstico: teoria e prática da Emenda Constitucional 72, de 2013. Curitiba: Juruá, 2013, p. 235-246.

ORGANIZAÇÃO INTERNACIONAL DO TRABALHO - OIT. Trabalho doméstico no Brasil: rumo ao reconhecimento institucional. Brasília: ILO, 2010. E-book.

Disponível em: <http:/ / www.ilo.org/wcmsp5/groups/public/---americas/---rolima/---ilo-brasilia/documents/publication/wcms_230639.pdf > . Acesso em: 16 maio 2017.

PERRINI, Valdyr. Empregados domésticos: a fictícia isonomia. In: GUNTHER, Luiz Eduardo; MANDALOZZO, Silvana Souza Netto (Coords.). Trabalho doméstico: teoria e prática da Emenda Constitucional 72, de 2013. Curitiba: Juruá, 2013, p. 257269 . 
REALE, Miguel. Filosofia do Direito. 20. ed. São Paulo: Saraiva, 2011. E-book. Disponível em: <http:/ / www.univates.br/biblioteca/e-books-minha-biblioeca?isbn= 9788502136557>. Acesso em: 21 maio. 2017.

SABADELL, Ana Lucia. Manual de sociologia jurídica: introdução a uma leitura externa do direito. 6. ed. rev., atual. e ampl. São Paulo: Editora Revista dos Tribunais, 2013.

SILVA, José Afonso da. Aplicabilidade das Normas Constitucionais. $7^{\mathrm{a}}$. ed. São Paulo: Malheiros, 2007.

STRECK, Lenio Luiz; MORAIS, José Luiz Bolzan de. Ciência política e teoria do Estado. 5. ed. rev. atual. Porto Alegre: Livraria do Advogado, 2006.

TITTONI, Jaqueline. Trabalho, poder e sujeição: trajetórias entre o emprego, o desemprego e os "novos" modos de trabalhar. Porto Alegre: Dom Quixote, 2007.

WEBER, Max. Economia e sociedade: fundamentos da sociologia compreensiva. 4. ed. Brasília: Universidade de Brasília, 2012. 